\title{
Metastatic Gastric Adenocarcinoma
}

National Cancer Institute

\section{Source}

National Cancer Institute. Metastatic Gastric Adenocarcinoma. NCI Thesaurus. Code C153319.

A gastric adenocarcinoma that has spread from its original site of growth to another anatomic site. 